\title{
Synaptic Interactions between Primate Precentral Cortex Neurons Revealed by Spike-Triggered Averaging of Intracellular Membrane Potentials In Vivo
}

\author{
Michikazu Matsumura, ${ }^{1}$ Dao-fen Chen, ${ }^{2}$ Toshiyuki Sawaguchi, ${ }^{1}$ Kisou Kubota, ${ }^{1}$ and Eberhard E. Fetz ${ }^{2}$ \\ ${ }^{1}$ Department of Neurophysiology, Primate Research Institute, Kyoto University, Kanrin, Inuyama, Aichi 484, Japan, and \\ ${ }^{2}$ Department of Physiology and Biophysics and Regional Primate Research Center, University of Washington, Seattle, \\ Washington 98195-7290
}

To document synaptic interactions between neurons in the precentral cortex of macaque monkeys, we recorded in vivo the intracellular (IC) membrane potentials of cortical neurons simultaneously with extracellular (EC) action potentials of neighboring cells. The synaptic potentials correlated with EC spikes were obtained by spike-triggered averages (STA) of the IC membrane potentials for 373 cell pairs recorded in anesthetized and awake behaving monkeys. Sixty-three STAs (17\%) showed excitatory postsynaptic potentials (EPSPs), beginning after the trigger spike. Pure EPSPs had onset latencies of $0.9 \pm 0.7$ msec (mean \pm SD) and amplitudes of $226 \pm 130 \mu \mathrm{V}$. Sixteen STAs (4\%) showed postspike inhibitory postsynaptic potentials (IPSPs), with onset latencies of $0.4 \pm 0.4 \mathrm{msec}$ and amplitudes of $-274 \pm 188 \mu \mathrm{V}$. The most common waveform, observed in $82 \%$ of the STAs with features, was a broad depolarization straddling the trigger spikes, reflecting synchronized synaptic input to both IC and EC neurons. These average synchronous excitation potentials (ASEPs) began $14.3 \pm 6.6 \mathrm{msec}$ before the trigger spike and had amplitudes of $1064 \pm 867 \mu \mathrm{V}$. Twenty- three STAs (6\%) showed an average synchronous inhibitory potential (ASIP): a hyperpolarization beginning before the trigger spike and reflecting IPSPs produced by a group of local inhibitory cells synchronized with the trigger cell. ASIPs had an onset latency of $-5.5 \pm 2.7 \mathrm{msec}$ and amplitude of $-589 \pm$ $502 \mu \mathrm{V}$. Combinations of synchronous and postspike potentials were also observed. Successive recordings provided examples of convergent and divergent connections between EC and IC cells. Neuron pairs with depolarizing postsynaptic potentials (PSPs) in the STA yielded peaks in the cross-correlograms of the IC and EC action potentials; the peak area was proportional to the amplitude of the PSP. These data suggest that a significantly larger proportion of cortical neurons interact through synchronous activity than through simple serial interactions; moreover, synchronous excitation affected more widely separated cell pairs than EPSPs and IPSPs, which were seen most often among the closest cells.

Key words: synaptic interactions; spike-triggered average; synaptic potentials; precentral cortex; primate; synchrony
The functional operations of motor cortex depend critically on the synaptic interactions mediated by intrinsic neuronal connections. Intracortical connections have been documented anatomically by various tracing techniques (Peters and Jones, 1984; White, 1989; Huntley and Jones, 1991; Keller, 1993a,b; Keller and Asanuma, 1993; Lund et al., 1993). The physiological effects mediated by these connections have been elucidated in vivo by stimulation and cross-correlation. Asanuma and Rosen (1973) evoked monosynaptic excitatory postsynaptic potentials (EPSPs) in motor cortex neurons by intracortical microstimulation of adjacent cortical sites and concluded that monosynaptic connections were limited to neuron pairs located within a tangential distance of $0.5 \mathrm{~mm}$. Others have cross-correlated the extracellular (EC) spike trains of adjacent precentral neurons to reveal the effect of synaptic con-

\footnotetext{
Received Jan. 16, 1996; revised Sept. 12, 1996; accepted Sept. 16, 1996.

This study was supported by a grant of the Ministry of Education (Japan), the Human Frontiers Science Program, and National Institutes of Health Grants NS12542 and RR00166. The major part of this work was completed by D.-F.C. as a partial fulfillment of the requirement for a $\mathrm{PhD}$ at the University of Washington. We gratefully acknowledge the histological assistance of Ms. Takako Miwa and Ms Kyoko Watanabe-Sawaguchi. We thank Jonathan Garlid and Larry Shupe for their technical assistance and Ms. Kate Elias for editorial help.

Correspondence should be addressed to Prof. Eberhard E. Fetz, Department of Physiology and Biophysics, University of Washington, Seattle, WA 98195-7290.

Dr. Matsumura's present address: Faculty of Integrated Human Studies, Kyoto University, Yoshida-Nihonmatsu-cho, Sakyo-ku, Kyoto 606-01, Japan.

Copyright (C) 1996 Society for Neuroscience $0270-6474 / 96 / 167757-11 \$ 05.00 / 0$
}

nections on firing probability (Allum et al., 1982; Murphy et al., 1985; Kwan et al., 1987; Smith, 1989; Fetz et al., 1991). Crosscorrelation studies suggest that intrinsic synaptic connections in primate motor cortex are largely confined to cells within $1 \mathrm{~mm}$.

These techniques have limited power to resolve synaptic interactions. Microstimulation may synchronously activate many neurons, including passing fibers, so the location of the neurons that mediate the evoked synaptic potentials remains unknown. The cross-correlation method requires a large number of spikes for two coactivated neurons to reveal the effects of synaptic connectivity (Moore et al., 1970; Kirkwood and Sears, 1978; Toyama et al., 1981a,b; Aertsen and Gerstein, 1985; Ts'o et al., 1986; Fetz et al., 1991). In motoneurons, small EPSPs $(<80 \mu \mathrm{V})$ may not even generate a cross-correlation peak with several thousand pulses (Cope et al., 1987). In practice, the cross-correlograms are often dominated by central peaks generated by synchronous input to the neurons, which may conceal the more subtle effects of serial synaptic connections.

These limitations can be overcome in part by spike-triggered averaging (STA) of intracellular (IC) membrane potentials. The STA technique was originally developed to document unitary inputs to spinal motoneurons (Jack et al., 1971; Mendell and Henneman, 1971) and has been applied in studies of rat sensorimotor cortex (Thomson et al., 1988, 1993a,b), cat sensorimotor cortex (Kang et al., 1988; Zarzecki et al., 1989), cat visual cortex 
(Komatsu et al., 1988; Mason et al., 1991), and primate motor cortex (Matsumura and Kubota, 1984). The number of triggers required to detect monosynaptic connections in STAs is typically an order of magnitude less than that required to reveal crosscorrelogram features (Cope et al., 1987). Cortical slices provide excellent recording stability for such STAs, but they eliminate much of the remaining nervous system and potentially compromise connections between the recorded neurons. The optimal approach to documenting synaptic interactions is STA in a normal milieu in vivo. The technical difficulty of obtaining the requisite simultaneous IC and EC recordings in vivo is offset by the ability to also determine the cells' responses to natural stimulation and their relationship to behavioral events.

In this study, we used STAs to analyze synaptic interactions between pairs of neurons in motor cortex of unanesthetized and lightly anesthetized macaques. Preliminary results have been presented in abstract form (Matsumura and Kubota, 1984; Matsumura et al., 1989, 1990; Chen and Fetz, 1993).

\section{MATERIALS AND METHODS}

Surgical preparation and recording. Recordings were obtained from 22 hemispheres of 13 chronically prepared macaques weighing $3.2-6.2 \mathrm{~kg}$ (three Macaca mulatta; three M. fuscata, two M. fascicularis, and five M. nemestrina). For the initial sterile implant surgery, the monkeys were deeply anesthetized with sodium pentobarbital (Nembutal, Abbott, 35 $\mathrm{mg} / \mathrm{kg}$, i.p.) or with halothane. The skull was exposed, and 10-12 small stainless steel or vitallium screws were implanted. Two stainless steel tubes were cemented in parallel on the skull over frontal and occipital areas. A concentric bipolar electrode or insulated acupuncture needle was usually implanted for stimulation of the pyramidal tract at the medullary level (anterior-posterior, $=0.0 \mathrm{~mm}$; lateral, $=1.5 \mathrm{~mm}$ ). The exposed skull was covered with a thin layer of dental acrylic, and the monkey was treated with antibiotics to prevent infection.

Recording sessions were initiated after the monkeys had recovered for at least $7 \mathrm{~d}$. On each recording day, the monkey was given a small dose of ketamine or Sernylan $(0.5 \mathrm{mg} / \mathrm{kg}$, i.m. $)$ and anesthetized with halothane (1\%, with $2-3 \mathrm{l} / \mathrm{min}$ of oxygen and $1 \mathrm{l} / \mathrm{min}$ of nitrous oxide). The monkey was seated in the primate chair, and its head was attached to a stereotaxic frame via the implanted tubes (for details, see Matsumura, 1979, his Fig. 1). The stereotaxic frame provided support and repeatable reference coordinates for the electrode carriers. A small elliptical hole $(\sim 2 \times 3$ $\mathrm{mm}$ ) was drilled through the acrylic and the skull at a site within the region bounded by A5-A20 and L3-L20, an area that covers the anterior portion of the central gyrus. The dura was incised with a fine needle (26 gauge hypodermic) to expose the surface of the cortex.

Under binocular vision electrodes for IC and EC recording were inserted into the cortex with independently movable stereotaxic carriers (Narishige SM-15 and David Kopf). The EC electrode was inserted in a vertical stereotaxic direction, and the IC electrode was inserted at an angle of $10-20^{\circ}$ from vertical in the parasagittal plane. The IC electrode was advanced by a pulse-stepping microdrive (Narishige, MO-71, or Burleigh Inchworm). After electrode tips were placed in the superficial cortical layer, the hole in the skull was filled with $4 \%$ agar dissolved in saline to dampen cortical pulsations. For recordings in the waking state, the halothane was turned off and the monkey allowed to recover from the anesthesia for at least $30 \mathrm{~min}$. When the monkey began performing the task, the pipettes were advanced to record IC and EC neuronal activity simultaneously. Recordings were obtained from 10 hemispheres while the monkey performed a motor response with the contralateral hand; two animals performed a visual reaction-time task (Sawaguchi et al., 1986a), and five performed an isometric wrist flexion-extension task (Cheney and Fetz, 1980).

IC recordings were obtained with glass micropipettes $(2 \mathrm{~mm}$ outer diameter) filled with $3 \mathrm{M} \mathrm{KCl}$ or K-methylsulfate with resistance between 10 and $40 \mathrm{M} \Omega$. The EC electrode was a single- or multi-barreled glass micropipette. The single pipettes were broken at the tip to $\sim 2 \mu \mathrm{m}$ and filled with $0.5 \mathrm{M} \mathrm{Na-glutamate}$ for both recording and iontophoresis. In most of the experiments, more stable recordings of isolated EC unit activity were obtained with double-barreled pipettes containing a carbon fiber of $7 \mu \mathrm{m}$ diameter (Toray, Toreca-3000) in one barrel (ArmstrongJames and Miller, 1979). The carbon fiber was exposed for 5-50 $\mu \mathrm{m}$ at the

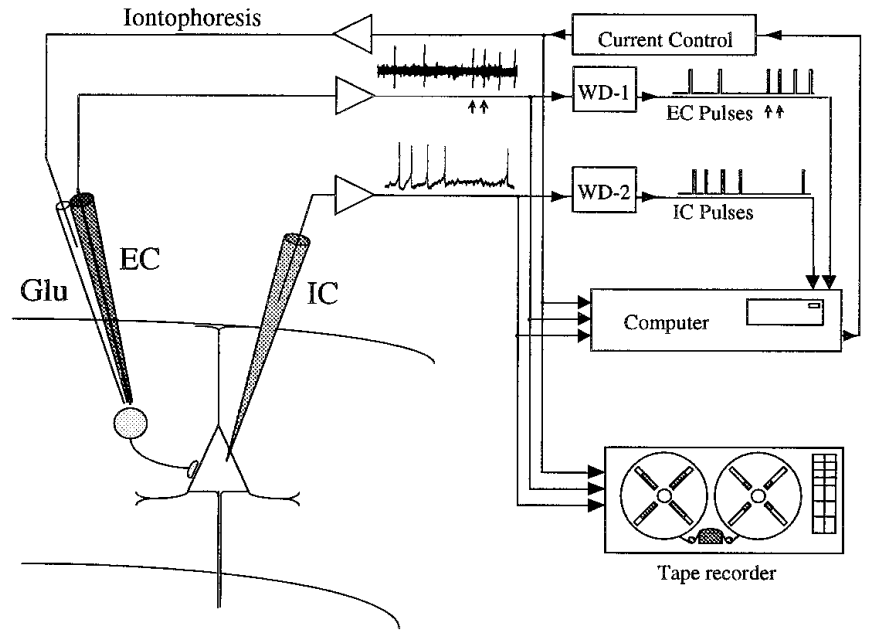

Figure 1. Schematic of cortical recording arrangement. Amplified signals obtained from IC electrode $(I C)$ and EC electrode $(E C)$ were recorded on tape and led to window discriminators $(W D)$ and to a computer for STA. The only EC pulses accepted for STA were those occurring in the absence of IC pulses (like the two indicated by arrows). Recorded data were analyzed in a similar manner off-line. To facilitate generation of EC action potentials, Na-glutamate could be iontophoretically applied through a second barrel $(G l u)$. (Note: The schematic drawings of the cells in this figure and Figure 4 should not be interpreted as implying particular cell types.)

tip of the pipette, and electric signals were led to an amplifier via $\mathrm{KCl}$ medium. The other barrel was filled with Na-glutamate $(10 \mathrm{~mm})$ to activate the isolated single unit(s) iontophoretically. The carbon fiber barrel was connected to an $\mathrm{AC}$ amplifier, and the glutamate side was connected to a constant-current isolation amplifier for application of iontophoretic anodal current of up to $70 \mathrm{nA}$ (Dia Medical, DPI-30, or Axon Instruments Axoprobe). A small platinum-plated pin implanted near the recording site was used as a reference electrode. The signals from the IC electrode were amplified to provide both low-gain DC records $(0-10 \mathrm{kHz})$ and high-gain $\mathrm{AC}$ records $(1 \mathrm{~Hz}$ to $10 \mathrm{kHz})$. All signals were recorded at $0-5 \mathrm{kHz}$ bandwidth on an 8- or 14-channel FM tape recorder (TEAC R-30 or Honeywell 101).

Spike-triggered averaging. Simultaneous recordings of IC membrane potential and EC unit activity obtained from pairs of cortical neurons were stored on analog magnetic tape for off-line analysis by STA. In many cases, particularly in anesthetized monkeys, the EC neurons were activated by iontophoretically applied Na-glutamate. This procedure favors somatodendritic recording and avoids activation of passing fibers; it also reduces the proportion of spikes driven by common synaptic input to the $\mathrm{EC}$ and IC neurons.

A schematic diagram of the experimental procedure is shown in Figure 1. The IC membrane potential was led to the signal input of a hardware averager (Nihon Kohden, ATAC-210), which averaged sweeps after the trigger, or to PDP-1173 averager, which included events preceding the trigger. Time-amplitude window discriminators (BAK, DIS-1) were used to generate pulses from action potentials in the EC and IC records. The EC pulses were used to trigger the STA and correlograms. The IC pulses were used to reject sweeps in the STA that would contain IC action potentials and were also used to compile cross-correlograms of EC and IC spikes. The minimum number of sweeps to detect a monosynaptic connection in an STA was taken as 100, although most averages included many more events. In a few exceptional cases, the potentials were large enough for us to judge synaptic interactions with sweeps of $<100$. IC recordings from neurons with large baseline fluctuations attributable to obvious mechanical instabilities were excluded from analysis.

Histology and reconstruction of the recording sites. To mark the recording sites, anodal and cathodal currents of $10 \mu \mathrm{A}$ for each polarity were passed for $10 \mathrm{sec}$ through the carbon fiber to make coagulate deposits at EC sites (Sawaguchi et al., 1986b). After each recording session (lasting 2-6 hr), the electrodes were withdrawn from the cortex without changing the electrode carrier positions. With the monkey lightly anesthetized with ketamine, antibiotics were applied to the cortex and the hole in the skull 


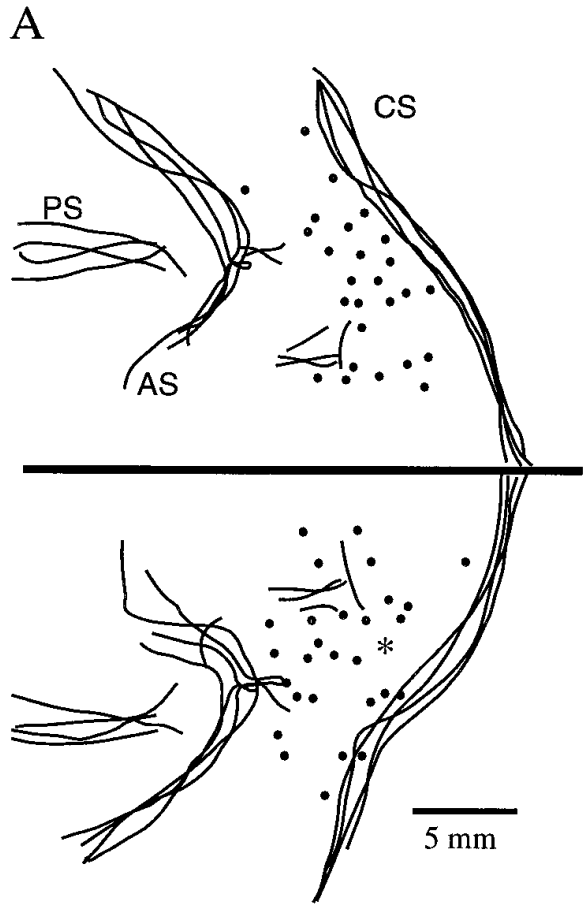

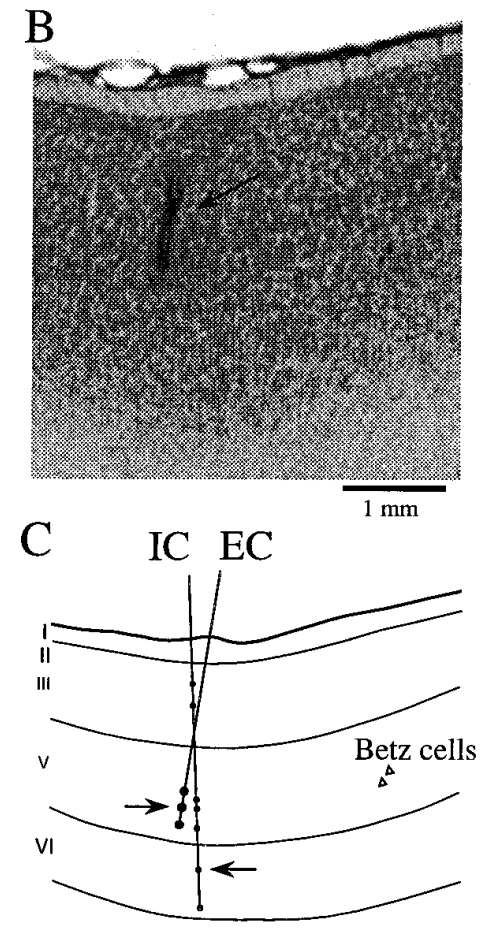

Figure 2. Cortical sites of EC and IC recordings. $A$, Surface view of the penetration sites of EC and IC electrode pairs. Eight hemispheres of four monkeys are superimposed on a plane, in which penetration sites of the electrode pairs are marked as dots. Data from other monkeys were recorded from similar locations. $B$, Parasagittal section of a recording site (marked by an asterisk in $A$ ). The EC electrode track was indicated by blood cells and glia. $C$, Drawing of the recording sites, derived from $B$. Straight lines indicate the EC and IC electrode tracks; dots along tracks show sites of the recorded cells. Arrows indicate the pair whose STA is illustrated in Figure $4 B$. was closed with dental cement. The monkey was removed from the recording chair, returned to its cage, and allowed to recover for at least $36 \mathrm{hr}$ before the next recording session.

The three-dimensional configuration of the two electrodes was measured after each session by repositioning the electrodes at the coordinates of the recordings. The angles of the electrodes and distances between their tips were measured with the aid of binocular magnification at every recording position, and these coordinates were later compared with histological sections.

At the end of the experiment, most of the monkeys were perfused with saline followed by $10 \%$ formalin under deep Nembutal anesthesia. The brain was post-fixed in $30 \%$ sucrose-formalin solution. Before the brain tissue was cut for histology, the surface was photographed to guide subsequent reconstruction. The tissue was cut either coronally or parasagittally into $100 \mu \mathrm{m}$ serial sections and stained by standard Nissl methods. The entry points of the recording electrodes were easily detected by connective tissue on the cortical surface and by glia or blood cells along the penetrating electrode track. The recording sites were identified with the aid of the depth reading of the electrode carrier and carbon deposits in the section.

\section{RESULTS}

A total of 889 pairs of simultaneous IC and EC recordings in the precentral cortex were obtained from 158 penetrations in 22 hemispheres of 13 monkeys. The area surveyed extended from medial leg region (lateral $=3 \mathrm{~mm}$ ) to lateral hand-face region (lateral $=20 \mathrm{~mm}$ ), as illustrated in Figure $2 A$. Of these pairs, 612 were recorded long enough for us to calculate STAs. Data were derived from 237 EC-IC pairs recorded in awake, behaving monkeys and 375 pairs recorded while the monkeys were anesthetized. The resting membrane potentials for these IC cells (calculated with reference to the potential measured on exit from the cells) ranged from -45 to $-65 \mathrm{mV}$. Spike-related features were seen in 411 of these STAs. The fact that STA features reflected membrane potentials uncontaminated by possible field potentials was confirmed by several observations: (1) STAs compiled with the electrode outside the cell had features with different shapes and with amplitudes an order of magnitude smaller than STAs of IC potentials, and (2) polarizing currents affected the IC STA fea- tures in ways expected from changes in driving force (Eccles, 1964; Thomson et al., 1988; Baranyi et al., 1993a,b).

The cortical location of most recording sites could be histologically reconstructed. The parasagittal section in Figure $2 B$ shows the site of an EC electrode track traversing the cortical layers perpendicularly; the electrode tracks usually could be identified by gliosis. The location of the IC electrode was calculated from the reconstructed configuration of the two electrodes (see Materials and Methods). This session yielded seven IC recordings and three EC recordings at the sites illustrated in the schematic drawing of the cortical layers in Figure $2 C$. Six of the seven pairs revealed features in the STAs, including the IPSP in Figure $4 B$ (bottom).

\section{Averaged monosynaptic postsynaptic potentials (PSPs)}

Examples of the recorded and averaged potentials obtained in an anesthetized monkey are shown in Figure 3. The top traces $(A)$ show action potentials of two spontaneously active EC units (top trace) recorded simultaneously with the IC membrane potential of a neighboring neuron (bottom trace). The recording sites of the IC and EC neurons were separated by $\sim 0.5 \mathrm{~mm}$ in the tangential direction $(B)$. The STA triggered by the larger unit $(L-u)$ showed a depolarizing deflection beginning after the trigger (at the beginning of the sweep), suggesting a monosynaptic excitatory connection between the large unit and the IC neuron.

STAs compiled from the smaller action potentials $(S-u)$ did not show any significant membrane potential deflections in the same number of sweeps. A control average of the same IC membrane potential during this recording period triggered from pulses generated regularly at $20 \mathrm{~Hz}$ did not produce significant deflections (Ctrl). In STAs that began with the trigger, such control averages provided an assessment of the noise level of the averaged membrane potential. Clear STA peaks that exceeded the maximum fluctuation of the control average were judged to reflect spikerelated synaptic events.

Four basic types of synaptic interactions between the triggering 
A
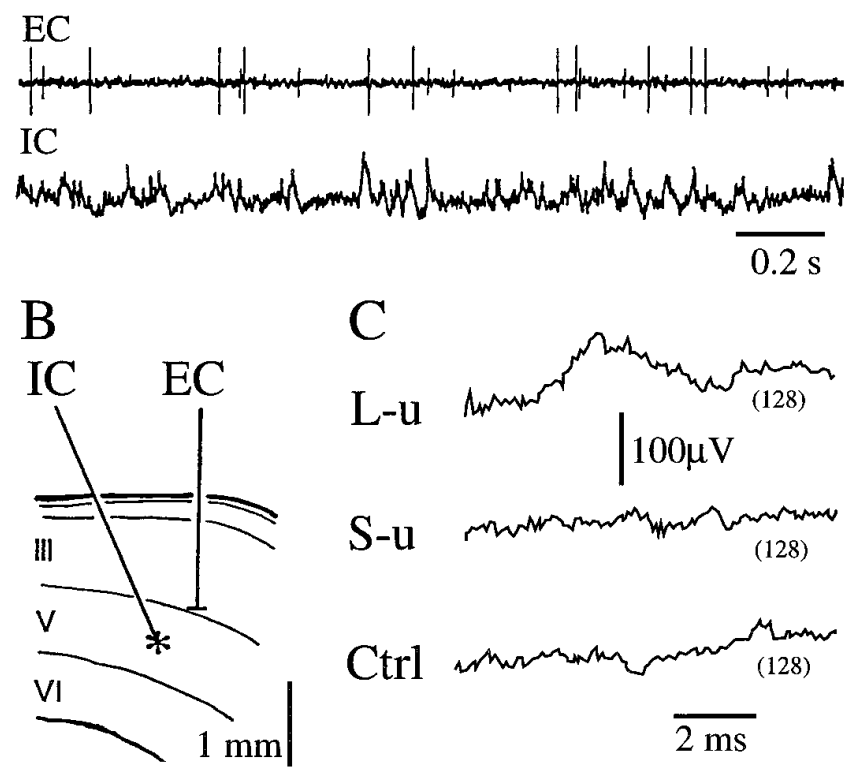

Figure 3. Examples of EC and IC recordings and STAs. $A$, Simultaneous recording of EC cell spikes and IC membrane potential. Two different EC units, with large and small action potentials, were spontaneously active under the anesthetized conditions. $B$, Schematic cross-section of cortex showing the IC and EC recording sites. $C$, STAs compiled from action potentials of the larger unit $(L-u)$ showing an EPSP. Trigger spikes occurred at beginning of sweep for this figure and Figures 9 and 10. STAs compiled from the smaller action potentials $(S-u)$ did not show any significant membrane potential deflections in the same numbers $(n=128)$ of sweeps. A control average of the same IC membrane potential during this recording period triggered from pulses generated regularly at $20 \mathrm{~Hz}$ did not produce significant deflections ( $\mathrm{Ctrl})$.

EC cell and the IC cell were identified on the basis of the polarity and the relative onset times of deflections in the STA. Examples are illustrated in Figure 4, along with schematic diagrams of the likely mediating synaptic connections. Transient depolarizing and hyperpolarizing potentials with clear onsets after the trigger spike were identified as EPSPs and IPSPs, respectively. Potentials that began before the trigger spike were attributed to synaptic input from populations of cells synchronized with the trigger cell. The most common spike-related feature was a depolarization with prespike onset called average synchronous excitation potential (ASEP). In addition, a newly described form of hyperpolarizing potential beginning before the trigger was called average synchronous inhibitory potential (ASIP). The proportion of these types of features encountered in different monkeys is summarized in Table 1. The parameters of these spike-related potentials measured in the "cleanest" examples (i.e., excluding cases that had combinations of these basic features or that showed evidence of periodic oscillations) are summarized in Table 2.

Serial EPSPs were identified by depolarizations that began shortly after the trigger spike, rapidly reached a peak, and gradually decayed. With $\mathrm{KCl}$ or K-citrate electrodes, the amplitudes of unitary EPSPs $(n=15)$ had a mean value of $125 \pm 45 \mu \mathrm{V}$ (SD) (range, 40-200 $\mu \mathrm{V}$ ). With K-methylsulfate electrodes, 63 of 505 $(12 \%)$ of the analyzed cell pairs showed serial EPSPs, either alone $(n=28)$ or in conjunction with ASEPs $(n=35)$. (These 63 pairs represent $17 \%$ of the 373 pairs that showed features in the STAs.)
To compare parameters under similar recording conditions, quantitative analysis was done for cells recorded with K-methylsulfate and STAs that had a prespike baseline. The amplitudes of the isolated EPSPs ranged from 75 to $525 \mu \mathrm{V}$ (Fig. 5), with a mean of $226 \pm 130 \mu \mathrm{V}$. The EPSP amplitudes in unanesthetized animals were similar to those in anesthetized monkeys.

The onsets of the EPSPs had a mean latency of $0.9 \pm 0.7 \mathrm{msec}$ (Fig. 6). The $0-100 \%$ rise times ranged from 2 to $12.2 \mathrm{msec}$, with a mean of $6.3 \pm 2.6 \mathrm{msec}$. The $10-90 \%$ rise times ranged from 1.8 to $9 \mathrm{msec}$, with a mean of $4.8 \pm 2.1 \mathrm{msec}$. There was no significant relationship between rise time and amplitude of EPSPs (Fig. 7). The duration of the EPSP half-width, defined as the duration measured at half of the peak amplitude, was $13.1 \pm 6.5 \mathrm{msec}$. There were no statistically significant relationships among these parameters except for the expected relationship between rise time and half-width.

Postspike IPSPs were identified by transient hyperpolarizations that began after the onset of the trigger spike (Fig. 4). As shown below, the polarity of the IPSP could be reversed when a hyperpolarizing current was injected through the IC electrode (see Fig. $10,4 b, c)$. Usually, hyperpolarizing potentials became apparent when the IC cell was depolarized below $-60 \mu \mathrm{V}$ by positive current injection or by deteriorated recording conditions.

With methylsulfate electrodes, pure IPSPs occurred in 16 of 373 (4\%) of the STAs showing features. IPSP amplitudes ranged from 58 to $641 \mu \mathrm{V}$, with a mean of $274 \pm 188 \mu \mathrm{V}$ (Fig. 5). The onset latencies of IPSPs varied from 0.1 to $1.4 \mathrm{msec}$ (Fig. 6), with a mean of $0.4 \pm 0.4 \mathrm{msec}$. IPSPs had $0-100 \%$ rise times of $7.9 \pm 2.6$ msec, on average longer than those of EPSPs.

The feature seen most frequently in STAs was the ASEP, a broad depolarization beginning before the trigger spike. Pure ASEPs occurred in $64 \%$ of the STAs with features, and an additional $18 \%$ was combined with other potentials. Onset times of ASEPs ranged from $-38 \mathrm{msec}$ to $-0.5 \mathrm{msec}$, with a mean of $-14.3 \pm 6.6 \mathrm{msec}$ (Fig. 6). ASEP peaks tended to occur after the trigger spike (at $3.6 \pm 3.4 \mathrm{msec}$ ). As plotted in Figure 5, the peak amplitudes of the ASEPs ranged from $58 \mu \mathrm{V}$ to $3.9 \mathrm{mV}$, with a mean of $1064 \pm 867 \mu \mathrm{V}$. The $0-100 \%$ rise times of ASEPs were longer than those of unitary PSPs: $17.8 \pm 6.6 \mathrm{msec}$. There was no significant relationship between rise times and amplitudes of ASEPs (Fig. 7).

Depolarizing the IC cells commonly generated STAs with a hyperpolarizing potential beginning before the trigger spike. These ASIPs had a mean onset latency of $-5.5 \pm 2.7 \mathrm{msec}$ (Fig. $6)$, significantly shorter than the pretrigger onset times of most ASEPs. ASIP amplitudes ranged from $139 \mu \mathrm{V}$ to $2.25 \mathrm{mV}$, with a mean of $589 \pm 502 \mu \mathrm{V}$ (Fig. 5). The $0-100 \%$ rise time of ASIPs was $10.6 \pm 2.6 \mathrm{msec}$, only slightly longer than that of IPSPs. In many cases, the rising phase of the ASIP showed a deflection indicative of a superimposed IPSP (Fig. $8 B$ ). These observations suggest that the ASIP represents the synaptic potential produced by a group of synchronously activated inhibitory cells, including the trigger cell (Fig. 4, bottom). This was directly confirmed for two EC neurons recorded simultaneously, which both produced an ASIP in the same target neuron and also showed a synchrony peak in their cross-correlogram (Fig. 8C).

In many cases, serial PSPs superimposed on an ASEP could be distinguished (Fig. 8). The features of these superimposed PSPs did not differ from those of comparable PSPs seen in isolation, although their summation precluded quantitative measurements. The presence of a serial EPSP superimposed on an ASEP was deduced from 

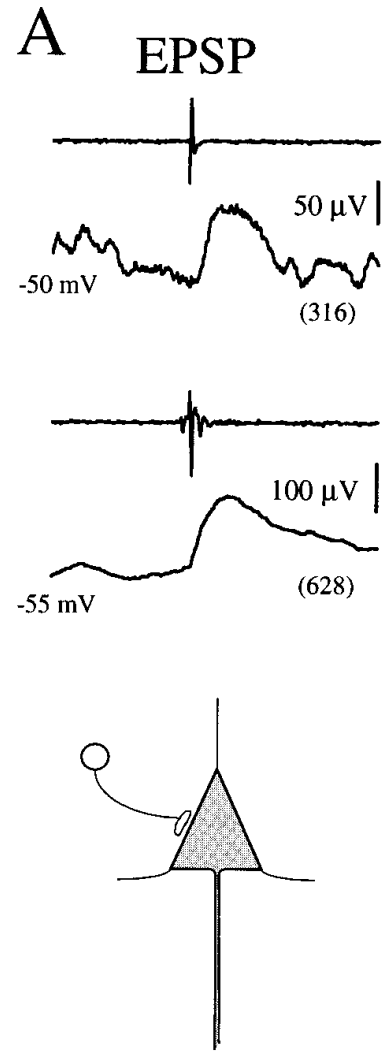
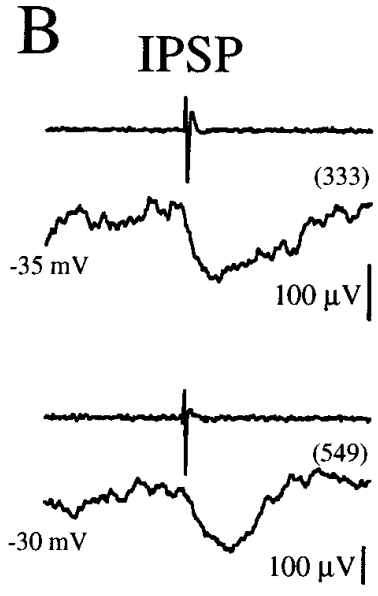

$100 \mu \mathrm{V} \mid$

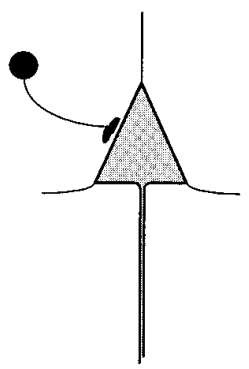

C ASEP
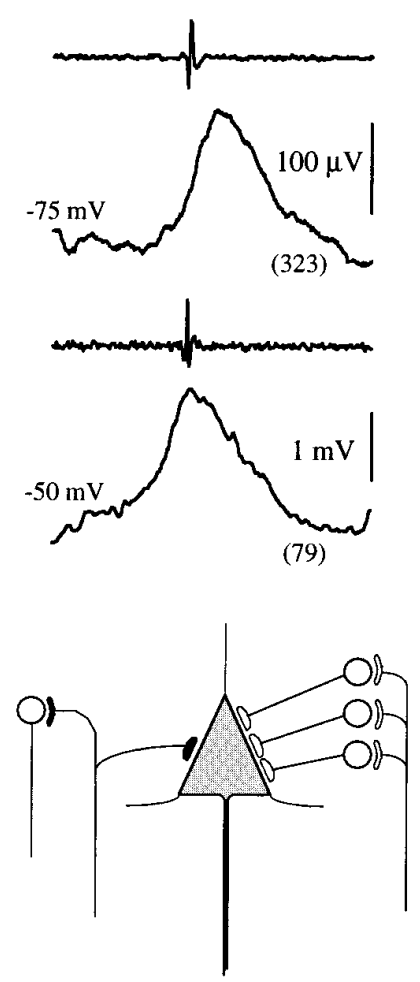
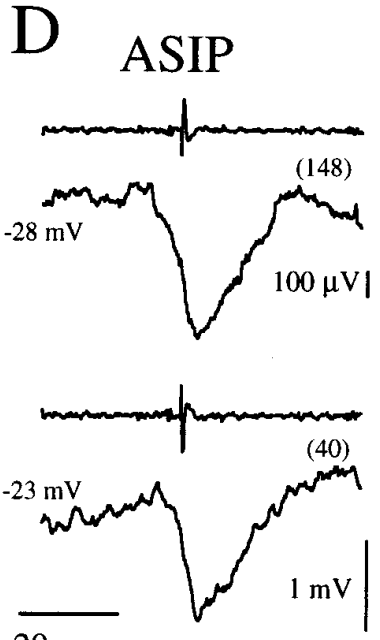

$20 \mathrm{msec}$.

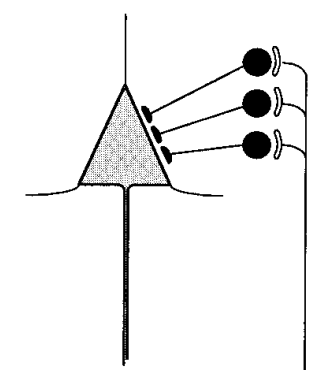

Figure 4. Four basic types of synaptic potentials revealed by STAs. Two examples are illustrated for each type (top). Averages show triggering EC spikes (top traces) and averaged IC membrane potentials (bottom traces). The number of sweeps in each STA is shown in parentheses. Possible synaptic circuits mediating effects are diagrammed at the bottom. Pyramidal-shaped units represent IC cells; the rest, EC cells. Open boutons designate excitatory synapses; solid boutons, inhibitory synapses; shaded boutons, either excitatory or inhibitory synapses.

Table 1. Distribution of STA features in different monkeys ${ }^{a}$

\begin{tabular}{|c|c|c|c|c|c|c|c|c|}
\hline Monkey & Condition & EPSP & ASEP & $\begin{array}{l}\text { ASEP } \\
+ \text { EPSP }\end{array}$ & IPSP & ASIP & $\begin{array}{l}\text { ASEP } \\
+ \text { IP }\end{array}$ & Total \\
\hline $\mathrm{R}$ & Anesthetized & 17 & 51 & 16 & & 1 & 1 & 86 \\
\hline M & Awake & 2 & 56 & 6 & 4 & 5 & 16 & 89 \\
\hline $\mathrm{C}$ & Awake & 2 & 29 & 4 & 2 & 3 & 4 & 44 \\
\hline $\mathrm{E}$ & Awake & 2 & 35 & 2 & & 2 & 6 & 47 \\
\hline
\end{tabular}

$\overline{{ }^{a} \text { All STAs included a prespike interval, allowing assessment of synchronous events. Inhibitory potentials (IP) associated with ASEP (last column) were either IPSP or ASIP }}$ (see Results).

a rise in the depolarization after the trigger (Fig. $8 A$ ). Such EPSPs could sometimes be confirmed by generating trigger spikes with glutamate; chemical activation increased the proportion of asynchronous spikes and the relative size of the serial EPSP. As illustrated in Figure $8 C$, some ASEPs were associated with hyperpolarizing deflections near the trigger. Because it was difficult to distinguish the onset of the hyperpolarizing deflection from the repolarization after the ASEP peak, we deemed it impossible to distinguish between ASIPs and IPSPs when they occurred in combination with ASEPs. Therefore, the inhibitory potentials associated with ASEPs are simply called IPs in Table 1.

\section{Differences between synaptic potentials in anesthetized and unanesthetized monkeys}

The IC recordings in awake monkeys showed considerably more fluctuations in membrane potentials than recordings in anesthetized animals, indicating a higher level of synaptic activity. The proportions of the different types of potentials were comparable under the two conditions, and any differences could easily be attributable to factors other than anesthesia. The average amplitude of the ASEPs in awake animals (1125 \pm $1096 \mu \mathrm{V}, n=28$ ) was not significantly larger than ASEPs in anesthetized animals (952 $\pm 763 \mu \mathrm{V}, n=74)$, suggesting a 
Table 2. Parameters of basic synaptic interactions in $\mathrm{STAs}^{a}$

\begin{tabular}{lrrrr} 
& \multicolumn{1}{c}{ Amplitude } & \multicolumn{1}{c}{ Latency } & \multicolumn{1}{c}{ Rise time } & Duration \\
\hline EPSP & $226 \pm 130 \mu \mathrm{V}$ & $0.9 \pm 0.7 \mathrm{msec}$ & $6.3 \pm 2.6 \mathrm{msec}$ & $23.1 \pm 6.5 \mathrm{msec}$ \\
IPSP & $274 \pm 188 \mu \mathrm{V}$ & $0.4 \pm 0.4 \mathrm{msec}$ & $7.9 \pm 2.6 \mathrm{msec}$ & $24.6 \pm 4.2 \mathrm{msec}$ \\
ASEP & $1064 \pm 867 \mu \mathrm{V}$ & $-14.3 \pm 6.6 \mathrm{msec}$ & $17.8 \pm 6.6 \mathrm{msec}$ & $39.1 \pm 9.4 \mathrm{msec}$ \\
ASIP & $589 \pm 502 \mu \mathrm{V}$ & $-5.5 \pm 2.7 \mathrm{msec}$ & $10.6 \pm 2.6 \mathrm{msec}$ & $29.0 \pm 6.2 \mathrm{msec}$ \\
\hline
\end{tabular}

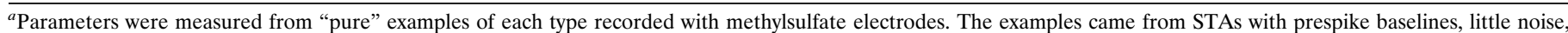
and no evidence of oscillatory activity; most were obtained from anesthetized animals.

comparable amount of synchronous activity under waking conditions. For the other types of potentials, there were too few cases to support statistically meaningful differences between awake and anesthetized conditions.

\section{Convergence and divergence of monosynaptic connection}

STAs for the same IC cell compiled from multiple EC cells demonstrated that single IC neurons could receive convergent monosynaptic inputs from several neighboring neurons, as illustrated in Figure 9. While the IC cell (at the location shown by the asterisk) was being recorded, the carbon fiber electrode was withdrawn to isolate activity of different EC units at the sites indicated by dashes. Two of the EC units generated STAs with EPSPs, whereas the most superficial EC cells did not yield PSPs.

When the EC and IC electrodes were separated by $>1 \mathrm{~mm}$ horizontally, the probability of finding features in the STAs decreased (Fig. 9B). Figure $9 C$ shows STAs for six EC units isolated between layer III and layer VI, as indicated by dashes along the EC electrode track. All but one of the STAs showed positive deflections. The continuous rise at the trigger point in 2 and 4 suggests that these IC and EC neurons also received synchronous input (compare Figs. 4 and 8). In records that had clear postspike onsets of the EPSP (3, 5, and 6), latencies ranged from $1.2 \mathrm{msec}$ for the closest neuron pair to $3.0 \mathrm{msec}$ for the farthest pair.

We obtained 20 similar cases of long-term recording from a given IC cell with two to six different EC units. In 13 cases, multiple pairs showed synaptic interaction between the neurons, indicating convergent input to the IC neuron.

The STAs also revealed cases of single neurons projecting to multiple adjacent neurons. An example of multiple IC targets affected by divergent connections from a single EC neuron is shown in Figure 10. The superimposed sweeps (bottom left) show the action potentials of a large and small EC unit isolated at the location marked by an asterisk in the schematic cross-section (top left). While these two units were being recorded, the IC electrode was moved to obtain IC recordings from five neurons at the locations marked by dashes. The STAs obtained from the small EC unit (right column) revealed EPSPs in two of the five IC recordings (neurons 3 and 4). These EPSPs were voltagesensitive, showing higher amplitude when the membrane potential was hyperpolarized by current injection (record $4 b$ for $1 \mathrm{nA}$ and $4 c$ for $2 \mathrm{nA}$ ). STAs from the large EC cell (middle column) showed an IPSP that was reversed with hyperpolarization.

We obtained 28 cases of recordings that included long-term EC recording with two to five different IC recordings. In 10 cases, multiple IC cells showed the same postsynaptic effect from the EC neuron, suggesting divergent output from the trigger neurons.

\section{Relative location of EC and IC cells}

The estimated separation of the EC and IC cells exhibiting the different types of potentials in the STAs is illustrated in Figure 11, which plots the amplitudes of the potentials against the direct separation between electrode tips. Most of the EPSPs occurred for cell pairs separated by $<2.5 \mathrm{~mm}$. (Note that this direct separation includes both vertical and horizontal cortical distances.) The largest EPSPs tended to occur with the nearest neighbors. Similarly, most IPSPs and ASIPs occurred with pairs separated by $<2 \mathrm{~mm}$. In contrast, ASEPs were seen with pairs over longer distances and without any clear dependence of amplitude on separation.

\section{Relationship between PSPs and correlogram features}

To determine the effect of PSPs on firing probability, we also compiled cross-correlation histograms between the EC and IC action potentials for 30 pairs in which the IC neuron provided sufficient numbers of spikes to compile meaningful correlograms. As illustrated in Figure 12 (top), EPSPs and ASEPs generated cross-correlograms with peaks that aligned with the rising phase of the PSP. Indeed, for the 30 pairs, the widths of the crosscorrelogram peaks were on average directly proportional to the PSP rise times (linear fit: peak width $=1.0$ PSP rise time; $r=$ 0.65 ). The peak area (number of above-baseline counts in the correlogram peak) tended to increase with the amplitude of the PSP (Fig. 12). The linear regression of the correlogram peak area against PSP amplitude in millivolts had a slope of $0.3(r=0.66)$. This relationship would suggest that on average, the cortical PSPs produced 0.3 above-chance counts per millivolt.

\section{DISCUSSION}

Types of synaptic interaction between cortical neurons This study provides the first measures of synaptic interactions between neighboring neurons in precentral cortex of primates using STAs of membrane potentials recorded in vivo. The averaged membrane potential reveals the net synaptic input to the IC cell correlated with spikes of the EC cell. The four basic types of cortical synaptic interactions revealed by STAs consisted of serial and synchronous versions of excitatory and inhibitory potentials. Other STA features could be explained as combinations of these four basic forms. The proportion of STAs that showed spikerelated features cannot be determined precisely, because the number of STAs without features was not recorded systematically and this proportion can be made arbitrarily small, depending on the separation of the cells.

\section{Physiological properties of the averaged EPSPs}

Approximately $17 \%$ of the EC-IC pairs with significant averaged features showed EPSPs, either alone or in combination with ASEPs. This proportion is higher than the proportion of excitatory linkages obtained by cross-correlating spike trains of neighboring cortical cells (5\%; Smith, 1989), probably due to the higher sensitivity of detecting subthreshold synaptic potentials in STAs 

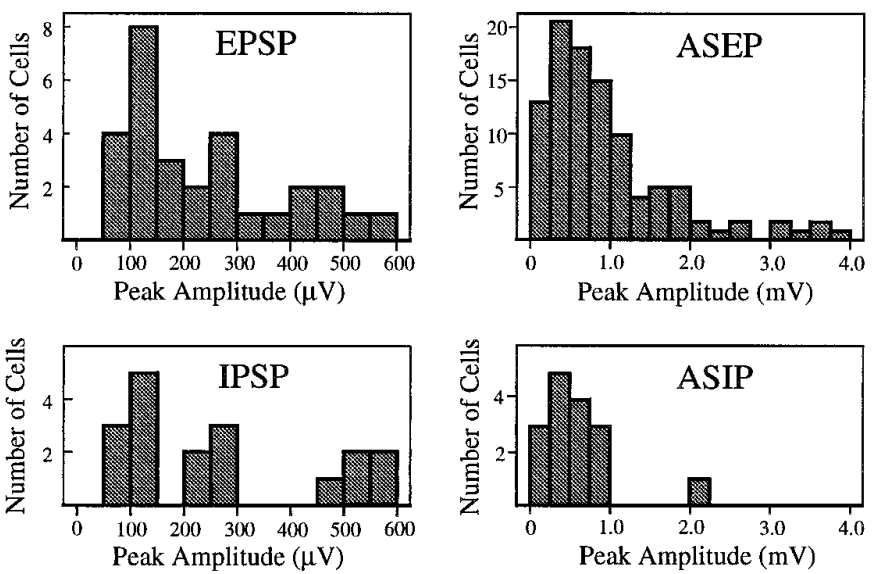

Figure 5. Amplitude distributions of synaptic potentials recorded with methylsulfate electrodes.
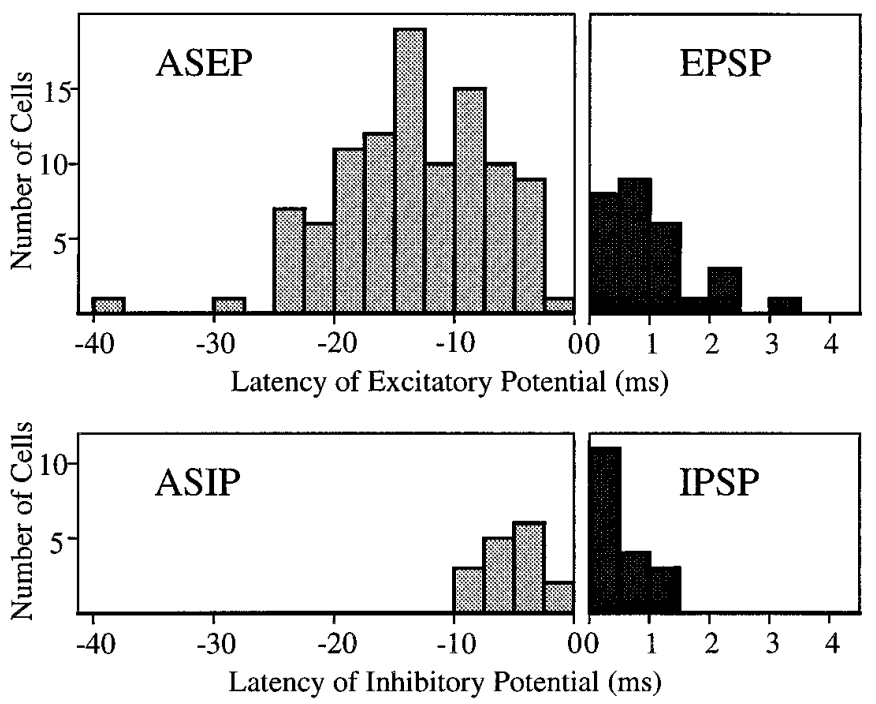

Figure 6. Onset latencies of synaptic potentials relative to onset of trigger spikes.

and a greater ability to identify an EPSP component superimposed on the ASEPs.

The mean amplitudes of the averaged EPSPs using $\mathrm{K}$-methylsulfate electrodes was $226 \mu \mathrm{V}$. They were obtained at various membrane potentials in different cells, ranging from -45 to $-65 \mathrm{mV}$. It should be noted that the fluctuations in membrane potentials occurring in vivo may introduce a significant source of variance in the measured parameters. Because prolonged stable recordings were difficult to maintain, the voltage dependence of EPSP amplitudes was not investigated routinely. The tested cases sometimes showed slight amplitude changes with depolarization, consistent with previous reports (Thomson et al., 1988; Baranyi et al., 1993a,b). The amplitudes of unitary EPSPs we obtained in primate motor cortex in vivo are compared with those from other cortical studies in Table 3. Larger unitary EPSPs were obtained in slices of rat sensorimotor cortex (Thomson et al., 1988, 1993a,b), perhaps because the cells in vitro had less background synaptic input to shunt the currents (Bernander et al., 1991).

The onset times of the EPSPs after the trigger spike were consistent with monosynaptic connections. Even those EPSPs
EPSP

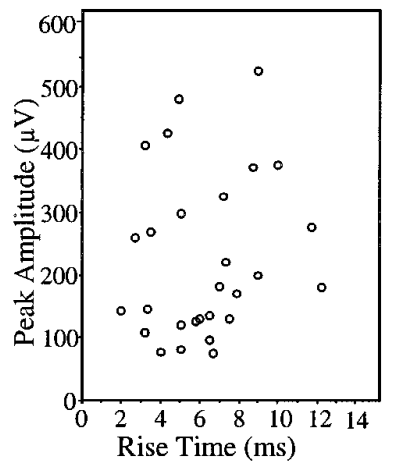

IPSP

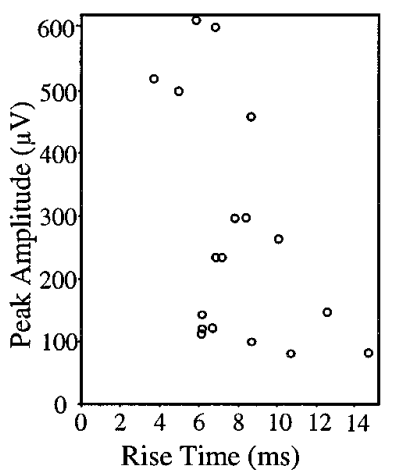

ASEP

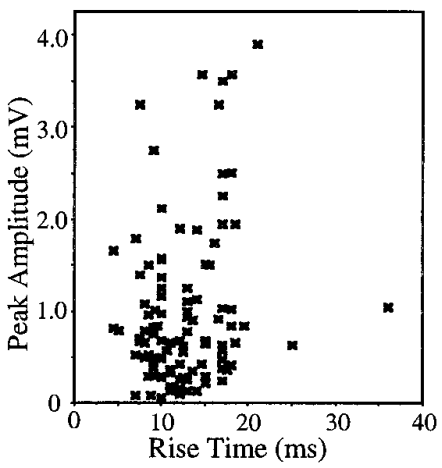

ASIP

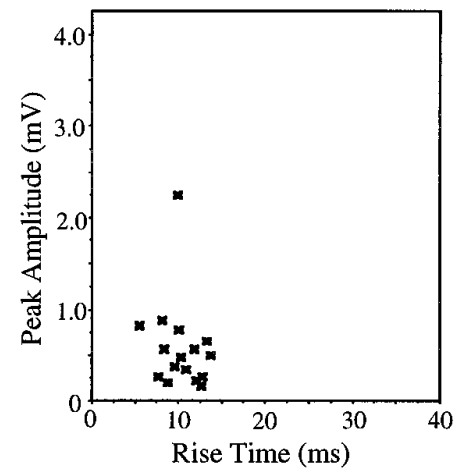

Figure 7. Rise times (0-100\%) of synaptic potentials plotted against amplitudes.

with delays exceeding 2 ms (e.g., Figs. 2, 6 and 9) are consistent with monosynaptic latencies found with STA in cortical slices (Komatsu et al., 1988), a preparation in which polysynaptic mediation is highly unlikely. The mean time course and half-width of the EPSPs in this study were comparable with measurements obtained in slice recordings from rats (Thomson et al., 1988) and cats (Komatsu et al., 1988), but were longer than those of recurrent EPSPs in cat sensorimotor cortex (Kang et al., 1988). Furthermore, the rise times of our EPSPs were longer than those obtained in the above studies. There was no significant relationship between rise time of the EPSP and amplitude. These differences may be due in part to the greater synaptic noise in our in vivo recordings, as well as to other factors. Some of the EPSPs could have included disynaptic components, although distinct inflections on the rising edge were not evident. The cable model for dendritic synapses predicts that EPSP time course is prolonged and EPSP amplitude is attenuated with increasing electronic distances from the soma (Rall, 1959), if the dendritic membrane is assumed to be passive. There is increasing evidence that voltage-dependent conductances are activated in dendrites of cerebral cortex neurons in vitro (Kim and Connors, 1993; Stuart and Sakmann, 1994; Schwindt and Crill, 1995), and in vivo (Pockberger, 1991). Such conductances could make the relationship between EPSP amplitude and duration more variable.

\section{Physiological properties of the ASEP}

Of EC-IC cell pairs with significant STA features, $82 \%$ showed membrane depolarizations that began before the EC trigger spikes, indicating a source of synchronous or common synaptic input. This proportion is close to that obtained in a crosscorrelation study (Smith, 1989) in which $90 \%$ of the cell pairs that 
A$$
\text { A }
$$$$
\text { a }
$$$$
\text { ASEP + EPSP }
$$$$
\text { EC }
$$

Figure 8. Combinations of synchronous and serial synaptic potentials. $A$, Two examples of an EPSP superimposed on ASEP. The post-trigger rise of the potential at arrow indicates onset of EPSP. B, Two examples of IPSP (onset at arrow) superimposed on ASIP. $C$, Two examples of IPs superimposed on ASEP. These records were obtained with two simultaneously recorded EC cells converging on the IC unit. The cross-correlogram of the EC cells (bottom) confirms their synchronous activation.
B

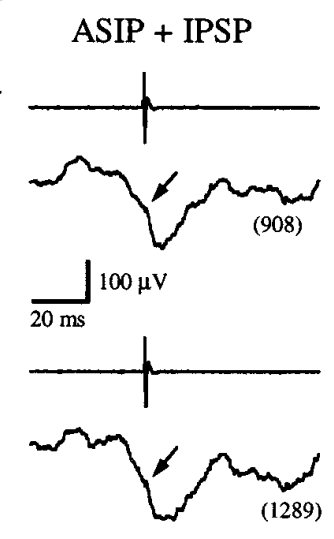

C

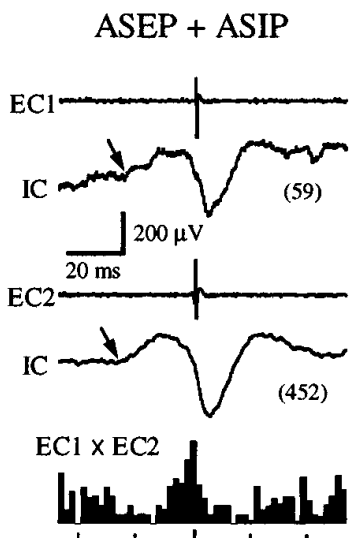

had significant correlogram features showed central peaks. Such synchrony peaks are a major feature of synaptic interactions in in vivo recordings in many other regions (for review, see Fetz et al., 1991). This study is the first to document the underlying ASEPs obtained in STAs of cortical neurons. On average, the ASEPs were $\sim 4.7$ times larger than the EPSPs, suggesting that to first approximation they could consist of about this many synchronous EPSPs. One type of neural mechanism that could generate the ASEPs is a common synaptic input to the EC and IC cells from the same presynaptic cell(s), as illustrated by the left side of the schematic in Figure $4 C$. Such common inputs could arise from afferent thalamocortical fibers, corticocortical axons, or local neurons, either excitatory or inhibitory (Moore et al., 1970; Jones, 1986), and would produce an "average common excitatory potential" (Kirkwood and Sears, 1978; Kirkwood, 1979). The second mechanism is synchronized synaptic input from separate but correlated presynaptic excitatory cells, which are synchronized with each other and with the trigger cell, as illustrated by the right side of the circuit diagram in Figure $4 C$.

A

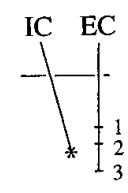

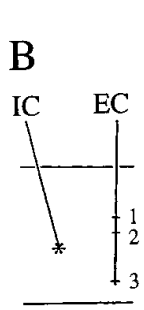

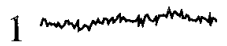

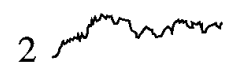

3
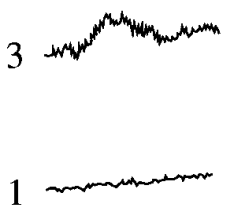

2

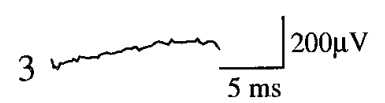

C

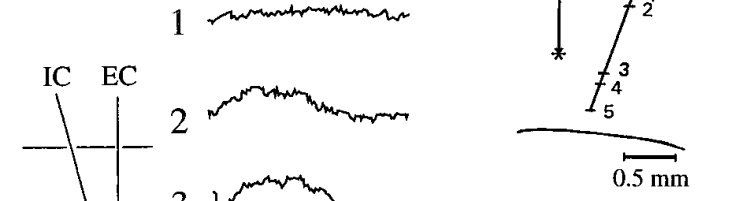

\section{Physiological properties of the averaged IPSP}

STAs revealed inhibitory potentials in $\sim 19 \%$ of EC-IC pairs. The proportion of inhibitory connections was probably underestimated, because inhibitory potentials were more likely to be detected in IC cells with depolarized membrane potentials, and STAs were usually not tested at depolarized potentials. In many cases, the recordings were simply too brief to make this test; moreover, depolarization usually generated action potentials in the IC cell, which precluded the averaging of subthreshold membrane potentials.

Of these averaged inhibitory potentials, only $4 \%$ of the cell pairs with STA features showed pure postspike hyperpolarizing potentials. The postspike latency of most IPSPs was consistent with a serial inhibitory connection, but some of the earliest may have included a synchrony component. Close examination of the

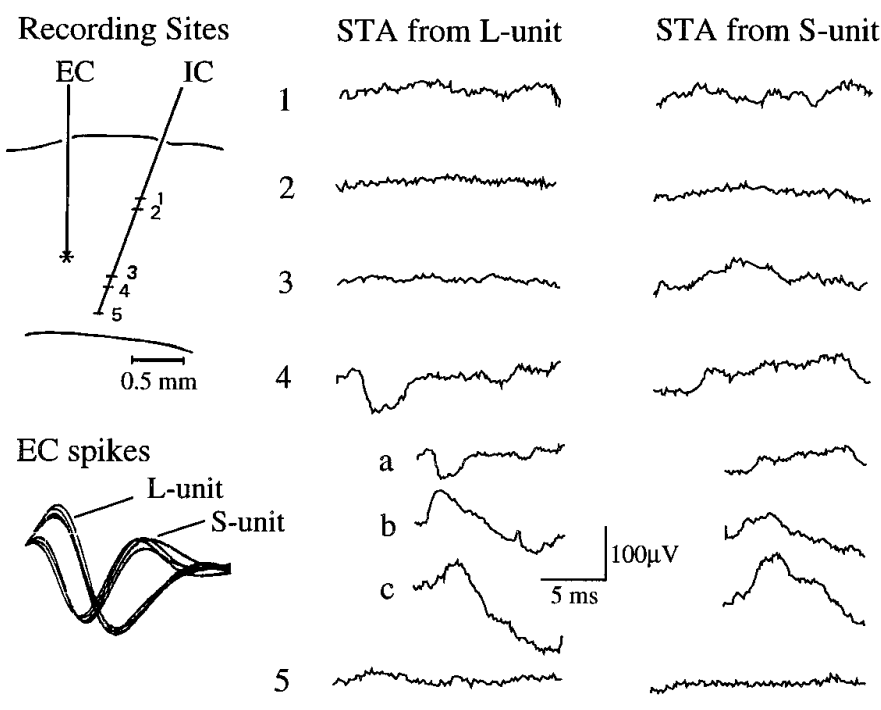

Figure 10. Divergent output effects from two EC cells to multiple IC cells. Activities of two EC units (action potentials at bottom left) were recorded from the same location (asterisk, top left). The STA from the larger EC unit showed an IPSP in the fourth IC neuron (middle). Hyperpolarizing current reversed the polarity of this IPSP. $a$, Control; $b$, reversed potential with $1.0 \mathrm{nA} ; c$, potential with $2.0 \mathrm{nA}$. STAs from the smaller EC unit (right column) showed EPSPs in the third and fourth IC neurons. With hyperpolarizing current, this potential increased in amplitude. $a$, Control; $b, 1.0 \mathrm{nA} ; c, 2.0 \mathrm{nA}$.
Figure 9. Convergent inputs from multiple ECs to the same IC cell. $A$, Schematic drawing of the EC and IC electrode tracks within the cortex and their recording locations (left) and the averaged potentials obtained by STA from each EC point. $B$, When the horizontal distance between the electrodes was $>1 \mathrm{~mm}$, serial synaptic interactions were rarely observed. $C$, When the distance was very close $(0.2 \mathrm{~mm})$, many EC cells showed EPSPs with various time courses. 


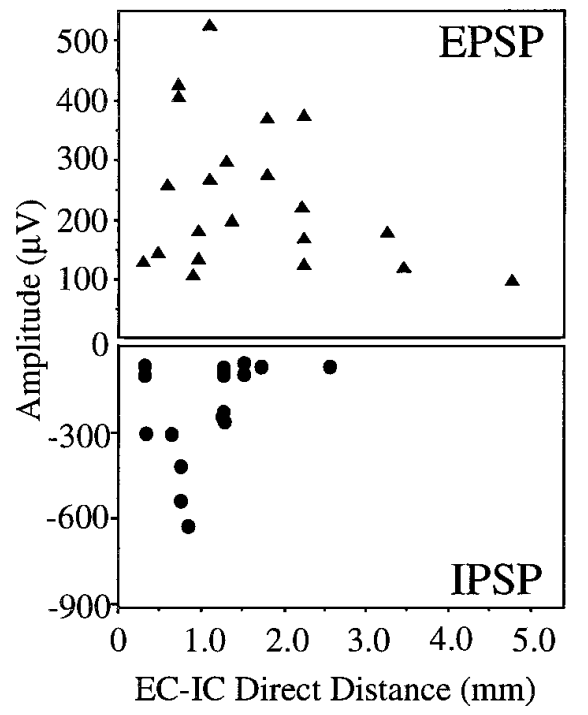

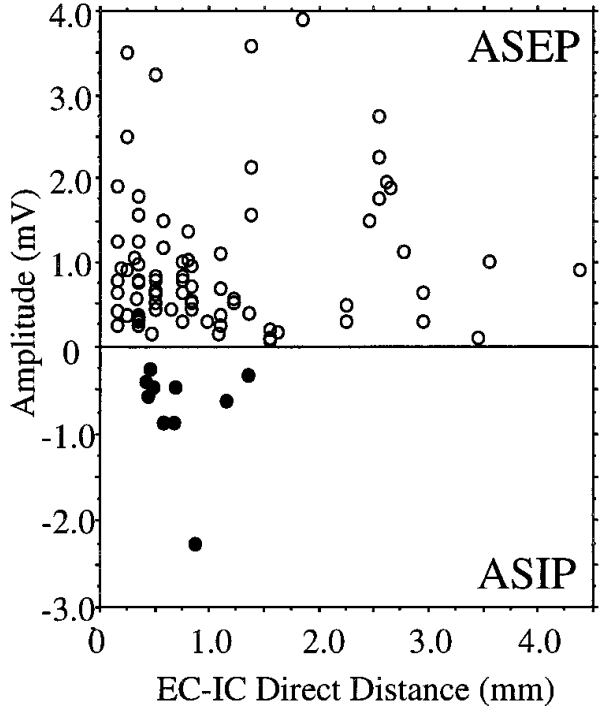

Figure 11. Amplitudes of synaptic potentials plotted against separation of EC and IC electrode tips.
ASIPs indicates that many also show a postspike deflection indicative of a superimposed IPSP. Thus, serial IPSPs may have been present in most of the hyperpolarizing events, if not all. In this

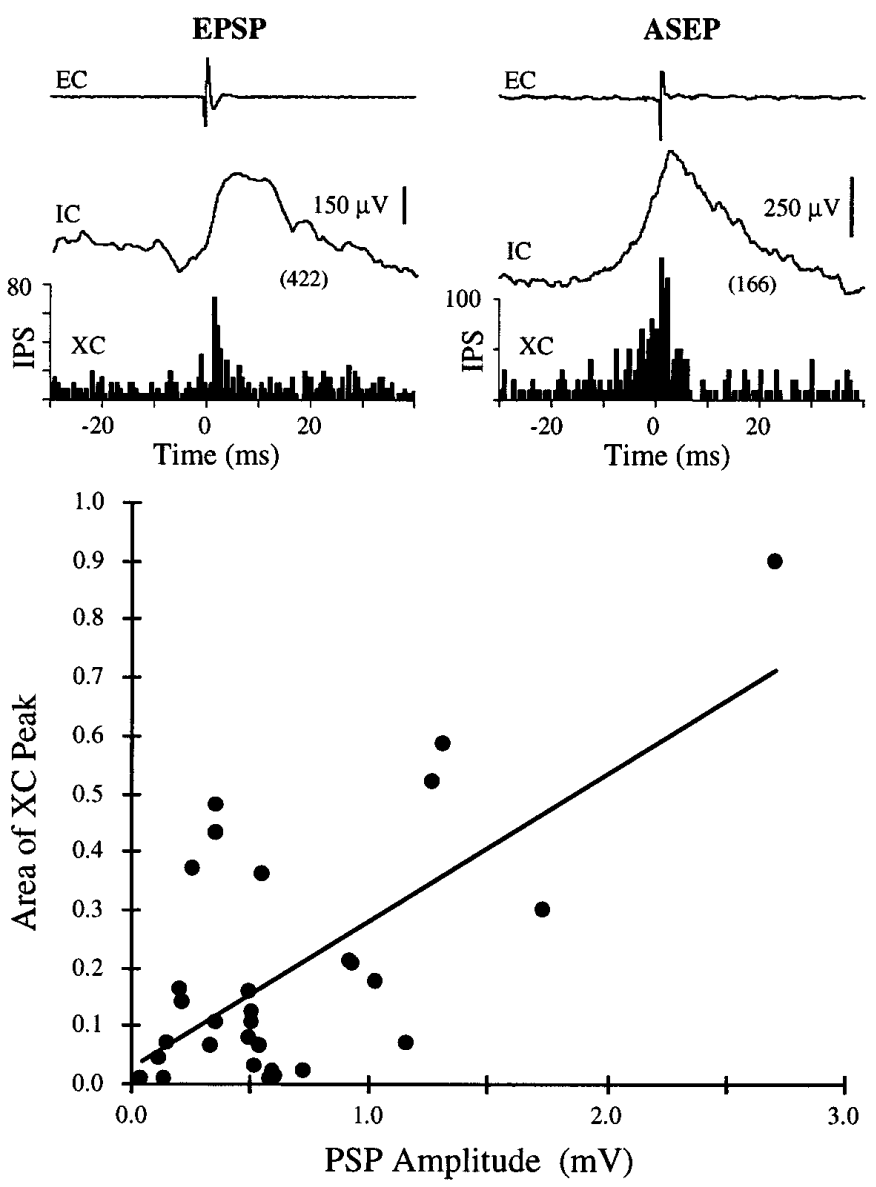

Figure 12. Relationship between synaptic potentials and crosscorrelograms. Examples (top) illustrate correlograms between EC and IC cells associated with EPSP (left) and ASEP (right). STAs were compiled in absence of IC spikes. Graph plots correlogram peak area (number of above-baseline counts in correlogram peak per trigger spike) against amplitude of synaptic potential in the STA. Linear regression line has slope of 0.3 spikes $/ \mathrm{mV}$. $\overline{\text { Table 3. Comparison of unitary EPSP and IPSP amplitudes in previous }}$ cortical studies

\begin{tabular}{llll} 
Preparation & Location & $\begin{array}{l}\text { Mean } \\
\text { (range) } \mu \mathrm{V}\end{array}$ & Study \\
\hline EPSP & & & \\
Cat & Motor cortex & $111(30-390)$ & Kang et al., 1988 \\
Cat* & Visual cortex & $132(60-210)$ & Komatsu et al., 1988 \\
Cat* & Visual cortex & $550(50-2080)$ & Mason et al., 1991 \\
Rat* & Sensorimotor & $410(79-2300)$ & Thomson et al., 1988 \\
Guinea pig* & Hippocampus & $131(30-665)$ & Sayer et al., 1990 \\
Monkey & Motor cortex & $226(75-525)$ & Present study \\
IPSP & & & \\
Cat* & Visual cortex & $90 \pm 50$ & Komatsu et al., 1988 \\
Guinea pig* & Hippocampus & $1300-3100$ & Miles et al., 1984 \\
Monkey & Motor cortex & $274(56-641)$ & Present study
\end{tabular}

In vitro preparations are indicated by an asterisk.

case, the number of inhibitory cells detected is closer to $19 \%$ of those generating spike-related effects.

The relatively infrequent identification of serial inhibition may be explained by the morphology of cortical inhibitory interneurons. Small cells with symmetric dendritic trees could have very focal EC fields and could be difficult to record with EC electrodes. Most GABAergic cells have short axonal projections to neurons in their immediate vicinity and inhibit only a localized area of cortex (Houser et al., 1984; DeFelipe and Jones, 1985). In cortex, very few GABAergic neurons have long horizontal projections (like the large basket cells) that could inhibit pyramidal cells in adjacent cortical columns (DeFelipe et al., 1986). These anatomical features may reduce the chances of obtaining cell pairs that have inhibitory connections.

The amplitudes of spike-triggered IPSPs recorded in this and other cortical studies are compared in Table 3. The mean amplitudes of our IPSPs were considerably larger than unitary IPSPs documented in cat visual cortex slices (Komatsu et al., 1988) and lumbar motoneurons (Jankowska and Roberts, 1972) but were smaller than those seen in guinea pig hippocampal slices (Miles and Wong, 1984). These differences may be attributable in part to differences in recording conditions and membrane polarization. 


\section{Physiological properties of the ASIP}

An unexpected finding in many STAs was a large hyperpolarizing synaptic potential that began before the trigger spike. These ASIPs were seen in pure form in $6 \%$ of the STA features and probably represent many of the inhibitory events associated with ASEPs (another 9\%). These inhibitory potentials had a time course similar to that of the serial IPSPs, but their onsets were earlier and their peak amplitudes $\sim 2.2$ times larger. We believe these early-onset hyperpolarizing potentials are probably produced by the synchronized activity of a group of cortical inhibitory interneurons. We also considered whether the early onset of the ASIP could be caused by a burst of spikes in a single inhibitory EC cell. Such burst activity would disperse the IPSP, generating an apparent early onset in the STA. Examination of the trigger autocorrelograms revealed burst patterns in only 3 of 23 "inhibitory" neurons, precluding this explanation for the nonbursting cells. Moreover, deconvolving the ASIP with the autocorrelogram of the bursting cells showed that the calculated effect of a single spike still had a clear prespike onset.

Several additional observations suggest that the ASIPs are caused by synchronous activity in a local population of inhibitory neurons. Unlike the ASEPs, which began on average $14 \mathrm{msec}$ before the EC triggers, the mean latency for the ASIPs was approximately $-5.5 \mathrm{msec}$. This is consistent with anatomical evidence that inhibitory actions in cortex originate from local intrinsic inhibitory interneurons (DeFelipe and Farinas, 1992). Moreover, the ASIPs were recorded only for cell pairs separated by $<1.5 \mathrm{~mm}$, in contrast to ASEPs, which extended to pairs separated by up to $4.5 \mathrm{~mm}$. The observation that two simultaneously recorded cells produced ASIPs on the same target IC cell and showed synchronous discharge in their correlogram directly supports the conclusion that ASIPs are generated by synchronous activity of a local group of inhibitory cells. In most, if not all, cases, the trigger cell itself would appear to be part of the inhibitory group.

\section{Relationship between PSPs and firing probability}

Synaptic interactions between individual neurons can be measured in two ways: by spike-related fluctuations in membrane potentials in STAs and by features in the cross-correlation histograms of spike trains. The relationship between these two measures of connectivity is of fundamental interest. The transform between PSPs and correlograms can be analyzed directly when both are documented for the same cells, as done previously for motoneurons (Fetz and Gustaffson, 1983; Cope et al., 1987; Gustaffson and McCrea, 1984) and cortical neurons (Reyes and Fetz, 1993). Our observations confirm previous findings that PSPs tend to trigger action potentials on their rising phase. In the present study, the number of above-baseline counts in the correlogram peak (its "area") tended to increase with PSP amplitude, with an increase of $0.3 \mathrm{impulses} / \mathrm{PSP} / \mathrm{mV}$. This is larger than the increase of $0.1 \mathrm{imp} / \mathrm{EPSP} / \mathrm{mV}$ obtained for unitary Ia EPSPs in cat motoneurons (Cope et al., 1987). It is also larger than the increase of $0.08 \mathrm{imp} / \mathrm{PSP} / \mathrm{mV}$ obtained in cat neocortical neurons studied in vitro (Reyes $\mathrm{AD}$, Fetz EE, unpublished observations). Taken at face value, these comparisons suggest that PSPs may have a greater efficacy in vivo than in vitro. However, another factor could also be relevant: in the present study, the PSP was averaged during pauses in IC firing, whereas the correlogram was obtained during normal activity. But normal firing could involve an increase in synchronous synaptic inputs that could boost the number of correlated IC spikes. This was not a factor in previous experiments, in which the postsynaptic action potentials were evoked by steady current injection, rather than by normally occurring synaptic inputs.

\section{Functional roles of intracortical synaptic interactions}

The fact that ASEPs were seen $\sim 10$ times more often than pure serial EPSPs suggests that cortical circuits operate more commonly via synchronous activity than isolated serial interactions. In $\sim 22 \%$ of the ASEP pairs, the trigger cell also had an excitatory or inhibitory connection to the IC cell. Thus, $78 \%$ of the ASEP pairs reflected synchronous firing of apparently unconnected cells, many of which were separated by greater distances than the connected cells. An even larger and more widely distributed population of cortical cells can be recruited into synchronous activity when it becomes oscillatory (Murthy and Fetz, 1992, 1996; König et al., 1995). Such oscillatory activity can be identified by periodic features in the STAs (Chen, 1993; Chen and Fetz, 1993) and was excluded in the present study.

Because we recorded many cell pairs during performance of motor responses, it is possible to ask whether the synaptic interactions revealed by STAs had a functionally consistent relationship to the cells' activity patterns during wrist movements. In general, inhibitory interactions (IPSPs and ASIPs) were more often seen in cells that had different activity patterns during voluntary movement. Conversely, excitatory interactions (EPSPs and ASEPs) were found more often in cells with similar discharge patterns during movements. The detailed interactions between cells of different layers during movement will be documented more fully in a subsequent paper.

\section{REFERENCES}

Aertsen AMHJ, Gerstein GL (1985) Evaluation of neuronal connectivity: sensitivity of cross-correlation. Brain Res 340:341-354.

Allum JHJ, Hepp-Reymond M-C, Gysin R (1982) Cross-correlation analysis of interneuronal connectivity in the motor cortex of the monkey. Brain Res 231:325-334.

Armstrong-James M, Miller J (1979) Carbon fiber microelectrodes. J Neurosci Methods 1:279-287.

Asanuma H, Rosen I (1973) Spread of mono- and polysynaptic connections within cat's motor cortex. Exp Brain Res 16:507-520.

Baranyi A, Szente MB, Woody CD (1993a) Electrophysiological characterization of different types of neurons recorded in vivo in the motor cortex of the cat. I. Patterns of firing activity and synaptic responses. J Neurophysiol 69:1850-1864.

Baranyi A, Szente MB, Woody CD (1993b) Electrophysiological characterization of different types of neurons recorded in vivo in the motor cortex of the cat. II. Membrane parameters, action potentials, currentinduced voltage responses and electrotonic structures. J Neurophysiol 69:1865-1879.

Bernander O, Douglas R, Martin KA, Koch C (1991) Synaptic background activity influences spatiotemporal integration in single pyramidal cells. Proc Natl Acad Sci USA 88:11569-11573.

Chen D-F (1993) Synaptic interactions between cortical neurons revealed by in vivo intracellular potentials. $\mathrm{PhD}$ dissertation, University of Washington, Seattle, WA.

Chen D-F, Fetz EE (1993) Effect of synchronous neural activity on synaptic transmission in primate cortex. Soc Neurosci Abstr 19:781.

Cheney PD, Fetz EE (1980) Functional classes of primate corticomotoneuronal cells and their relation to active force. J Neurophysiol 44:773-791.

Cope TC, Fetz EE, Matsumura M (1987) Cross-correlation assessment of synaptic strength of single Ia fibre connections with triceps surae motoneurones in cats. J Physiol (Lond) 390:161-188.

DeFelipe J, Farinas I (1992) The pyramidal neuron of the cerebral cortex: morphological and chemical characteristics of the synaptic inputs. Prog Neurobiol 39:563-607. 
DeFelipe J, Jones EG (1985) Vertical organization of the $\gamma$-aminobutyric acid-accumulating intrinsic neuronal systems in monkey cerebral cortex. J Neurosci 5:3246-3260.

DeFelipe J, Conley M, Jones EG (1986) Long-range focal collateralization of axons arising from corticocortical cells in monkey sensory-motor cortex. J Neurosci 6:3749-3766.

Eccles JC (1964) The physiology of synapses. Göttingen: Springer.

Fetz EE, Gustafsson B (1983) Relation between shapes of post-synaptic potentials and changes in firing probability of cat motoneurones. J Physiol (Lond) 341:387-410.

Fetz EE, Toyama K, Smith WS (1991) Synaptic interaction between cortical neurons. In: Cerebral cortex, Vol 9 (Peters A, Jones EG, eds), pp 1-47. New York: Plenum.

Gustafsson B, McCrae D (1984) Influence of stretch-evoked synaptic potentials on firing probability of cat spinal motoneurones. J Physiol (Lond) 347:431-451.

Houser CR, Vaughn JE, Hendry SHC, Jones EG, Peters A (1984) GABA neurons in the cerebral cortex. In: Cerebral cortex, Vol 2 (Jones EG, Peters A, eds), pp 63-90. New York: Plenum.

Huntley GW, Jones EG (1991) Relationship of intrinsic connections to forelimb movement representation in monkey motor cortex: a correlative anatomic and physiological study. J Neurophysiol 66:390-413.

Jack JB, Miller S, Porter R, Redman SJ (1971) The time course of minimal excitatory post-synaptic potentials evoked in spinal motoneurones by group Ia afferent fibres. J Physiol (Lond) 215:353-380.

Jankowska E, Roberts WJ (1972) Synaptic actions of single interneurones mediating reciprocal Ia inhibition of motoneurones. J Physiol (Lond) 222:623-642.

Jones EG (1986) Connectivity of the primate sensory-motor cortex. In: Cerebral cortex, Vol 5 (Jones EG, Peters A, eds), pp 113-183. New York: Plenum.

Kang Y, Endo K, Araki T (1988) Excitatory synaptic actions between pairs of neighboring pyramidal tract cells in the motor cortex. J Neurophysiol 59:636-647.

Keller A (1993a) Intrinsic connections between representation zones in the cat motor cortex. NeuroReport 4:515-518.

Keller A (1993b) Intrinsic synaptic organization of the motor cortex. Cereb Cortex 3:430-441.

Keller A, Asanuma H (1993) Synaptic relationships involving local axon collaterals of pyramidal neurons in the cat motor cortex. J Comp Neurol 336:229-242.

Kim HG, Connors BW (1993) Apical dendrites of the neocortex: correlation between sodium and calcium-dependent spiking and pyramidal cell morphology. J Neurosci 13:5301-5311.

Kirkwood PA (1979) On the use and interpretation of cross-correlation measurements in the mammalian central nervous system. $\mathrm{J}$ Neurosci Methods 1:107-132.

Kirkwood PA, Sears TA (1978) The synaptic connections to intercostal motoneurones as revealed by the average common excitation potential. J Physiol (Lond) 275:103-134.

Komatsu Y, Nakajima S, Toyama K, Fetz EE (1988) Intracortical connectivity revealed by spike-triggered averaging in slice preparations of cat visual cortex. Brain Res 442:359-362.

König P, Engel AK, Singer W (1995) Relation between oscillatory activity and long-range synchronization in cat visual cortex. Proc Natl Acad Sci USA 92:290-294.

Kuno M, Weakly JN (1972) Facilitation of monosynaptic excitatory synaptic potentials in spinal motoneurones. J Physiol (Lond) 224:271-286.

Kwan HC, Murphy JT, Wong YC (1987) Interaction between neurons in the precentral cortical zones controlling different joints. Brain Res 400:259-269.

Lund JS, Yoshioka T, Levitt JB (1993) Comparison of intrinsic connectivity in different areas of monkey cerebral cortex. Cereb Cortex 3:148-162.

Mason A, Nicoll A, Stratford K (1991) Synaptic transmission between individual pyramidal neurons of the rat visual cortex in vitro. J Neurosci 11:72-84.

Matsumura M (1979) Intracellular synaptic potentials of primate motor cortex neurons during voluntary movement. Brain Res 163:33-48.

Matsumura M, Kubota K (1984) Spatial distribution of neurons with monosynaptic inputs to adjacent neurons in the primary motor cortex. Soc Neurosci Abstr 9:492.

Matsumura M, Chen DF, Fetz EE (1989) Synaptic interaction between neighboring neurons in the primate motor cortex. Soc Neurosci Abstr $15: 281$.
Matsumura M, Chen DF, Fetz EE (1990) Relative location of synaptically interacting cells in primate precentral motor areas. Soc Neurosci Abstr 16:242.

Mendell LM, Henneman E (1971) Terminal of single Ia fibers: location, density and distribution within a pool of 300 homonymous motoneurons. J Neurophysiol 34:171-187.

Miles R, Wong RKS (1984) Unitary inhibitory synaptic potentials in the guinea-pig hippocampus in vitro. J Physiol (Lond) 356:79-113.

Moore GP, Segundo JP, Perkel DH, Levitan H (1970) Statistical signs of synaptic interaction in neurons. Biophys J 10:876-900.

Murphy JT, Kwan HC, Wong YC (1985) Cross correlation studies in primate motor cortex: synaptic interaction and shared input. Can J Neurol Sci 12:11-23.

Murthy VN, Fetz EE (1992) Coherent 25-35 Hz oscillations in the sensorimotor cortex of awake behaving monkeys. Proc Natl Acad Sci USA 89:5670-5674.

Murthy VN, Fetz EE (1996) Synchronization of neurons during local field potential oscillations in sensorimotor cortex of awake monkeys. J Neurophysiol, in press.

Peters A, Jones EG, editors (1984) Cerebral cortex, Vol 1, Cellular components of the cerebral cortex. New York: Plenum.

Pockberger H (1991) Electrophysiological and morphological properties of rat motor cortex neurons in vivo. Brain Res 539:181-190.

Rall W (1959) Core conductor theory and cable properties of neurons. In: Handbook of physiology, Sec 1, The nervous system, Vol I, Cellular biology of neurons (Brookhart J, Mountcastle VB, Kandel E, eds), pp 39-97. Bethesda: American Physiological Society.

Reyes AD, Fetz EE (1993) Two modes of interspike interval shortening by brief transient depolarizations in cat neocortical neurons. J Neurophysiol 69:1661-1672.

Sawaguchi T, Matsumura M, Kubota K (1986a) Dopamine modulates neuronal activities related to motor performance in the monkey prefrontal cortex. Brain Res 371:404-408.

Sawaguchi T, Matsumura M, Kubota K (1986b) Long-lasting marks of extracellularly recorded sitesby carbon fiber glass micropipettes in the frontal cortex of chronic monkeys. J Neurosci Methods 16:341-348.

Sayer RJ, Friedlander MJ, Redman SJ (1990) The time course and amplitude of EPSPs evoked at synapses between pairs of CA3-CA1 neurons in the hippocampal slice. J Neurosci 10:826-836.

Schwindt PC, Crill WE (1995) Amplification of synaptic current by persistent sodium conductance in apical dendrite of neocortical neurons. J Neurophysiol 74:2220-2224.

Smith WS (1989) Synaptic interaction between identified motor cortex neurons in the active primate., $\mathrm{PhD}$ dissertation, University of Washington, Seattle, WA.

Stuart GJ, Sakmann B (1994) Active propagation of somatic action potentials into neocortical pyramidal cell dendrites. Nature 367:69-72.

Thomson AM, Girdlestone D, West DC (1988) Voltage-dependent currents prolong single-axon postsynaptic potentials in layer III pyramidal neurons in rat neocortical slices. J Neurophysiol 60:1896-1907.

Thomson AM, Deuchars J, West DC (1993a) Single axon excitatory postsynaptic potentials in neocortical interneurons exhibit pronounced paired pulse facilitation. Neuroscience 54:347-360.

Thomson AM, Deuchars J, West DC (1993b) Large deep layer pyramidpyramid single axon EPSPs in slices of rat motor cortex display paired pulse and frequency-dependent depression, mediated presynaptically and self-facilitation, mediated postsynaptically. J Neurophysiol 70:2354-2369.

Toyama K, Kimura M, Tanaka K (1981a) Cross-correlation analysis of interneuronal connectivity in cat visual cortex. J Neurophysiol 46:191-201.

Toyama K, Kimura M, Tanaka K (1981b) Organization of cat visual cortex as investigated by cross-correlation technique. J Neurophysiol 46:202-214.

Ts'o DY, Gilbert CD, Wiesel TN (1986) Relationships between horizontal interactions and functional architecture in cat striate cortex as revealed by cross-correlation analysis. J Neurosci 6:1160-1170.

White EL (1989) Cortical circuits: synaptic organization of the cerebral cortex. Structure, function and theory. Boston: Birkhauser.

Zarzecki P, Gordon DC, Fetz EE (1989) Intracortical connectivity of cat motor cortex evaluated by spike-triggered averaging and crosscorrelation. Soc Neurosci Abstr 15:281. 